\title{
Bringing practice into theory: Reflective practice and attachment theory
}

\author{
Maree Foley, Mary Nash and Robyn Munford
}

Maree Foley is a PhD candidate in the Department of Management and International Business at the University of Auckland Business School, a NZ Registered Psychotherapist and full member of NZACAP.

Mary Nash is a Life Member of ANZASW and lectures at Massey University.

Robyn Munford is co-leader of a FRST-funded research project on young people's pathways to resilience and works in the School of Health and Social Services, Massey University.

\begin{abstract}
The relationship between social work practice and attachment theory has been longstanding across decades. While much attention has been paid to the use of attachment theory within specific social work practice settings, less attention has been focused on the use of attachment theory to guide the social worker in their practice based reflections. This article explores the potential relevance of attachment theory for use within a reflective practice setting. This exploration is based on key findings from a recent study conducted in Aotearoa New Zealand. A proposed beginning framework of attachment theory informed reflective practice is offered for practitioners to explore in their reflective practice.
\end{abstract}

\section{Introduction}

Exploration of the relationship between theory and practice has been a longstanding endeavour within many disciplines including social work (Longhofer \& Floersch, 2004; D'Cruz, Gillingham, \& Melendez, 2007, p.74). This paper explores the use of attachment theory to inform reflective practice and, in turn, to potentially inform social work practice. This exploration is based on a recent Aotearoa New Zealand Masters research study that explored the relationship between theory and practice, from the vantage point of the social worker (Foley, 2007). This paper begins by providing a brief overview of this study, including a review of current attachment theory literature for social work practitioner use. Next, a summary of the study's findings is reported.

The remainder of this paper attends to the authors' reflections on how the raw findings might usefully inform reflective practice. It is postulated that knowledge of attachment theory can be useful for the practitioner to increase understanding of both shared and unique protective and adaptive behaviours within a practice setting where their capacity to think, reflect and make meaningful connections may become compromised. Based on these postu- 
lations, an exploration of bringing key dynamics of social work practice with children and families into attachment theory is explored. This exploration is followed by the beginning formulations of an attachment theory informed reflective social work practice.

\section{Overview of the study}

This study began with a review of the literature on attachment theory and social work practice, where it was clear that interest in attachment theory as a relevant social work practice theory has been sustained over a number of decades (Bowlby 1969, 1973 and 1980; Ainsworth \& Bowlby, 1991; Cassidy and Shaver, 1999). As such a plethora of relevant literature for this study was found (Fahlberg, 1991; Howe, 2005; Howe, Brandon, Hinings \& Schofield, 1999; Nash, Munford, \& O’Donoghue, 2005; Atwool, 2006). Surprisingly, studies that investigated social work practitioners' knowledge of attachment theory to inform their practice, found that attachment theory knowledge was not as prominent as expected (Hesse, 1982; Grigsby, 1994; Hendemark, 2004). In addition, recommendations from these social work practice specific studies each implied a view that advocating for increased attachment theory oriented education would equate with the capacity to use this theory in practice. As such there seemed to be an underlying assumption within the recommendations of these studies that theoretical knowledge equates with use, and use amidst the real time and moments of the social work-client relationship.

Given the above paradoxical findings above, Foley (2007) conducted a study that sought to gather Aotearoa New Zealand data regarding the practice status of attachment theory and research developments as experienced by social workers within their social work practice with children and their families. While keeping in mind socio-culturalcontextual issues, the primary focus of this study was the microsphere of practice. This study endeavoured to understand the journey of a theory, attachment theory, through the vehicle of the social worker in their practice descriptions of using attachment theory to inform their practice.

In this qualitative phenomenological study (Van Manen, 1990), eight social workers who self-identified as being interested in and knowledgeable about attachment theory were interviewed and were invited to reflect on their experiences of putting attachment theory into social work practice with children and families. One of the interview questions included: 'What aspects of attachment theory have made the most sense to you as a social worker?' That is, most of the social workers in this study began their reflections not with accounts of attachment theory knowledge, but with their own responses to the theory.

Following these interviews, an analysis process (Colaizzi,1978; van Manen, 1990) ensued, guided by a key question: 'Are there identifiable patterns, implicit and or explicit, being used by the interviewed social workers in their processing of attachment theory as a social work practice theory, to inform child and family oriented social work?' The initial analysis focused on ascertaining from the descriptions an anticipated pattern of 'putting theory into practice'. However, the descriptions of these social workers in this study did not fit this pattern. Instead a different pattern was identified: That is, when the participants' responses were analysed, the self of the practitioner along with practice knowledge preceded any theoretical comment, reflecting a process more akin to 'Bringing practice into theory'(Foley, 2007). 
As the coded analysis continued, a general pattern emerged where it appeared that each social worker was bringing their experience of attachment theory along with their understandings to their practice. In turn, bringing social work practice into attachment theory became understood to represent a process where neither practice nor theory was privileged. Instead, privileged was the social worker. It was this finding that largely informed a key recommendation of this study:

Attachment theory as a relational theory requires a broadening of the potential scope of relevance within attachment theory informed social work practice theory to be inclusive of the social worker, the client and the social worker-client relationship (Foley, 2007, p. 138).

In addition, the attachment theory foundations prominent in this study were considered a useful theoretical framework to support re-positioning of the social worker to the centre of the theory - practice dance. As such, this paper returns to the relevant literature of this study but with a different purpose in mind: to view attachment theory as being potentially useful to inform the social worker about themselves and their relationships; and for this exploration to be supported and developed in a reflective practice structure.

\section{Re-viewing attachment theory for practitioner use}

While there are many comprehensive reviews of attachment theory across disciplines (Cassidy \& Shaver, 1999) within social work, attachment theory is commonly identified as most relevant to specific fields of practice such as the care and protection needs of infants and young children (Howe, 2005; Schofield \& Beek, 2006). While attachment theory is often associated with infants and young children, current studies have sought to examine the activation of the attachment system in adulthood at times of stress / distress (Mikulincer, Birnbaum, Woddies \& Nachmias, 2000; Mikulincer, Gillath \& Shaver, 2002). That is, to explore whether adults continue to seek out a significant other (someone in a caregiving role) at times of high stress, with the goal of that other providing relief and support that in turn facilitates exploration of possible problem-solving routes. It has been repeatedly found that under stress all adult participants 'underwent preconscious activation of the attachment system' (Mikulincer \& Shaver, 2003, p. 89). These findings highlight that the attachment system is relevant throughout the life span and optimally viewed in relationship to and with two other interdependent systems: the caregiver system and the exploratory system.

Central to these stress / distress-based understandings within attachment theory is the construct of 'the secure base' (Bowlby, 1988; Schofield \& Beek, 2005). In attachment theory, an experience of 'felt security'(Sroufe \& Waters, 1977, p. 1186) increases the capacity to experience stress without being overwhelmed. In turn 'felt security'encouraged exploration at difficult times, it kept problem solving mobile, creative and relational. Bowlby proposed that when 'felt security' at times of stress was compromised then one way to create security was to become self protective through using processes of the mind referred to as 'defensive exclusion' and/or 'selective exclusion' (Bowlby, 1980, p. 52). As a consequence of these mind processes, aspects of experience could be excluded from awareness and therefore not as readily available to remember, share and/or prompt help seeking to resolve the stress which was being experienced. 
Central to the development of attachment theory has been the development of the hypothesis that repeated experiences of the attachment-caregiving and exploratory system become internalised as implicit mental maps of how relationships when under stress best function. These maps, referred to as 'internal working models', are open to adaptation and change yet often remain unchanged in structure across generations (Cassidy \& Shaver, 1999). It is thought that the greater opportunity for felt security on offer from the caregiver system at times of high need/stress, the more open, dynamic and creative the exploratory system can remain for problem solving. In contrast, when 'felt security' is compromised in some way, it is more likely as Bretherton (1985) stated that if 'material is defensively excluded from awareness, it cannot be restructured or updated...'(p. 13).

Therefore attachment theory infers that in the presence of ongoing stress within the attachment-caregiver and exploratory systems, a working model exists of how relationships function when stress develops. In turn, this implicit model includes experiences and expectations of self concerning one's capacity to seek out and make use of help and support at the times it is most needed. Included also are experiences and expectations of how others are likely to respond to requests for help and support. For example, information can become repeatedly excluded for the purpose of self-protection from unbearable pain. The more information is excluded from attention and processing, the less responsive a person can become to considering new information that does not fit the current view of their relationships.

In summary, attachment theory advocates that at times of overwhelming stress / pressure, our capacity to experience stress / pressure and be able to think and act in ways to reduce the stress / pressure is related to the quality of the relationship that we have, or can in the present establish, with a secure base. In turn attachment theory asserts that the quality of relationship made possible with the sought-after secure base is influenced by the internal working model of relationships and the type of exclusion/inclusion defences activated to protect against any expected suffering specific to attachment-caregiving experiences. In addition the experience with the secure base at times of high stress impacts on the capacity and content possibilities of reflection.

\section{Bringing social work practice into attachment theory}

Social work with children and families is often conducted amidst high anxiety, uncertainty and emotion. Within this emotional context, the social worker is both ethically and professionally responsible to reflect, think and act with coherence. However, Fonagy, Steele and Steele (1991) assert that 'day-in, day-out, social workers (and their agencies) practise in emotionally demanding environments which trigger characteristic coping styles, defensive strategies and adaptive behaviours' (p. 205).

In addition, in a social work setting, the nature of social work service provision often structures the social worker-client relationship with the social worker in the helper/help provider role and the client in the helpee/help seeking role. Therefore, regardless of the social work field of practice, when a context of stress / pressure is recognised for the social worker and or the client, attachment theory can be relevant in understanding the following. First, unique responses of the social worker and the client to distress-stress; second, the impact of these responses on the capacity of the social worker and the client to reflect on and then become exploratory towards possible solutions; and third the social worker's 
practice capacity to enact the social work plan along with the client's capacity to experience being helped and supported.

In a social work relationship it is often the social worker who is working with the client to co-construct a secure base within the client's family and community. At best a secure base is where the conditions for ongoing experiences of 'felt security'are on offer. Within an attachment theory informed social worker-client relationship, it is the task of the social worker, in the role of helper to assess and, where possible, structure conditions for the client that will optimally provide the conditions for the client to experience 'felt security'.

While in principle it is easy to concur with the global social work goals of providing help, support and the conditions for felt security for clients, most social workers will have stories and experiences where help offered to another in need is rejected, not made use of, fought against. We know from practice that while some clients who meet the criteria for high needs, who have multiple needs, who concur with the social worker that they need help are also at times the most challenging to a social worker's sense of efficacy. Failure, fear and hopelessness can quickly overshadow the original quest to provide/offer social work service. In addition, some of these very clients with high needs, can also be the clients who are the most difficult to listen to and to spend time with. A social worker may feel embarrassed, ashamed, private about their own practice responses to these clients. For example, a social worker who wishes to provide help and support may repeatedly find themselves at work acting in ways that are unresponsive, inconsistent, avoiding responding to phone calls and dismissing or minimising a family's needs.

Recent social work practice research by Ruch (2005a; 2005b; 2007) advocates that for social workers to engage in best practice, social workers need organisational support to develop their reflective capacities. Ruch (2007) proposes one way to support social workers in this endeavour is to step up the secure base that their respective practice agencies offer to social workers to support them in their practice. Therefore, by increasing organisational support, a social worker is more likely to experience felt security within their organisation, in turn, increasing a social worker's reflective capacities (Ruch, 2005b, p. 111).

Attachment theory can further develop this proposition. Attachment theory can be useful to guide the reflection process concerning relationships that are functioning within stressful/overwhelming experiences / situations, and where these relationships reflect a helpeehelper dynamic. As such attachment theory could be used to inform reflective practice, the place where it is commonly agreed social workers bring themselves and their practice into view, for theoretical and practical review, often within a supervisory relationship.

\section{Bringing the social work practitioner into attachment theory: Reflective practice}

In addition to the original understandings espoused by Bowlby $(1969 ; 1973 ; 1980)$, Ainsworth and Bowlby (1991) plus the recent work on adult attachment (Mikulincer \& Shaver, 2003) three useful constructs have emerged from attachment theory research that have direct relevance to reflective social work practice: 'Coherence'(Main 1991); 'reflective functioning'(Fonagy et al., 1991) and 'mind-mindedness' (Meins, Fernyhough, Fradley \& Turkey, 2001). While there is not the space to delve into each of these constructs, they each extend an assump- 
tion in attachment theory: That what is held in mind of a relationship functions to guide what can be observed, acknowledged, and attended to in a way that provides the security seeker with relief.

As such, based on the theoretical exploration above, for a social worker in a caregiver, helper role, it is possible to hypothesise from an attachment theory perspective, that what is available for reflection, and the degree of relational capacity that can be sustained while reflecting, in turn impacts on the social worker's capacity to provide 'sensitive responding' (Ainsworth, Blehar, Waters \& Wall, 1978) to their client. That is to attune, to interpret and to respond within the client's time frame. Bowlby's constructs of selective and defensive exclusion, referred to above, function to self protect from experiencing affects and thoughts that are perceived as overwhelming and unbearable. As a consequence this impacts on what is available to be reflected on. Therefore, attachment theory does not assume that what we report, and have immediate access to for reflection, is all that there potentially is to reflect on. It assumes instead, that by increasing our capacity for 'reflective functioning'(Fonagy et al., 1991) and 'mind-mindedness'(Meins et al., 2001) we will come to know much more of what is there to be known within the helper-helpee relationship.

\section{A working model of attachment theory informed reflective social work practice}

While social work has a strong tradition of reflective models of social work practice (for example see: Redmond, 2004; Ruch, 2005a and 2005b), attachment theory provides a lens in which to view the reflective process itself and to gain greater understanding and empathy for what each social worker within each unique social work-client relationship can access of that relationship for reflection.

What follows is the beginning formulations of an attachment theory informed framework for reflective practice. Central to this formulation are two key attachment theory constructs: the attachment-caregiver and exploratory systems and the secure base. These key constructs in turn can inform the development of guiding questions for use within a reflective practice setting. As such, it is suggested here that the following needs consideration: the social worker's internal working model; how the social worker functions in the presence of intense affect and stress and how they relate to others when in a helper-caregiving role; knowledge about defensive exclusion strategies used, when they are used and with whom.

For the purposes of an attachment theory model of reflective practice:

Knowledge of self becomes inclusive of knowing how one feels, thinks and acts when stressed and when needing to be in a help provider role at this time. To develop attachment theory informed questions that are structured so that at all times the challenge to think and act in a relational way is present (Foley, 2007, p. 146).

A working example is presented in the diagram below: Secure-base reflective questions. This diagram has been developed from drawing on the work of Zeanah, Boris, Scott Heller, Hinshaw-Fuselier, Larrieu, Lewis, Palomino et al. (1997), who during infant-parent assessments keep in mind a key question throughout the process. That is: 'what it feels like to be this particular infant in this particular relationship with this particular caregiver at this particular time' (p. 186). The study showed it is possible to extend and adapt this key question to assist reflective practice concerning social worker-client relationships. 
For example, the diagram below portrays a reflective circle posing a number of questions, with the social worker taking in turn the position of the key relationships, and reflecting on what it is like to be in this position in relationship with self and others. These formulated questions are not intended to be exhaustive nor necessarily representative of all key relationships. They are but as working examples in which to begin to anchor the social worker in considering the interplay of multiple attachment-caregiver-exploratory systems within a single social work interaction.

Figure one. Secure-base reflective questions (Foley, 2007, p. 147).

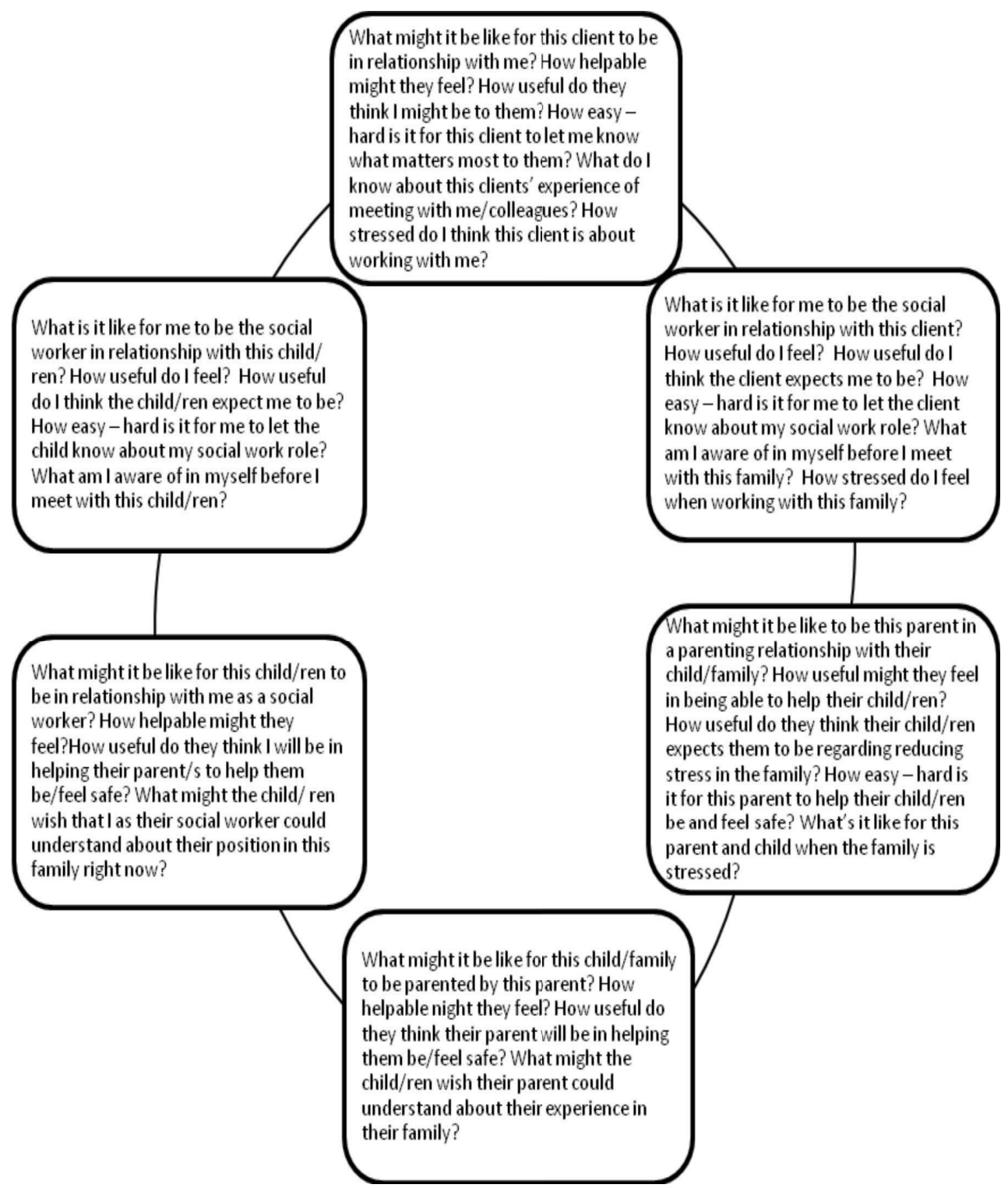


In addition it is suggested that following reflection on social worker-client experiences, that an attachment theory-informed framework of reflective practice include reflections on how to ensure as best as possible an experience of 'felt security' for both the social worker and the family as a precursor to any social work intervention. As such the following questions were formulated within the study as a guide to provide further relational support to the social worker and the family as an integral aspect of any other social work. The following practice based attachment theory informed questions are represented below in Table one.

Table one. Practice based attachment theory informed questions (Foley, 2007, p.148).

1. Based on what I have understood about the internal working model of help seeking-provision of this client/client family, what do I need to offer this client/client family to provide the conditions for them to have an experience of 'felt security'? What support might they need to optimally feel safe in receiving help and support?

2. What does the client/family need to offer to their own family, so as to provide the conditions for their own family to have an experience of 'felt security'? What support and/or systems would optimally provide the conditions for the family to experience efficacy and family belonging $/ \mathrm{mem}$ bership.

3. Based on what I know of my own internal working model of help seeking-provision, what do I need to be offered and receive from my team/colleagues for me to have an experience of 'felt security', so I can help this client/ client family?

4, What other key relationships and social resources might I consider as being useful to have on offer for this client family so as to provide further conditions for 'felt security'?

\section{Conclusion}

In conclusion, while attachment theory and social work have shared a longstanding relationship, the potential for social workers to use attachment theory for their own personal and professional development has been explored here. Highlighting the attachment-caregiver and exploratory system in relationship to the secure base and relating this to the social worker-client relationship, extends the potential use of attachment theory to any social work interaction functioning in a context of stress and/or distress. The above suggestions of how one might include these theoretical underpinnings into a reflective practice setting are the reflective fruit of research-based conversations with the social work participants who were generous enough to share their practice into theory approaches at work.

\section{References}

Ainsworth, M.D.S., Blehar, M.C., Waters, E., \& Wall, S. (1978). Patterns of attachment: A psychological study of the strange situation. U.S.A.: Lawrence Erlbaurn Associates.

Ainsworth, M.D.S., \& Bowlby, J. (1991). An ethological approach to personality development. American Psychologist, 46, 331-341.

Atwool, N. (2006). Attachment and resilience: Implications for children in care. Child Care in Practice, 12(4), 315-330.

Bowlby, J. (1969). Attachment and loss Vol.1: Attachment. London: The Hogarth Press.

Bowlby, J. (1973). Attachment and loss Vol.2: Separation, anxiety and anger. London: The Hogarth Press.

Bowlby, J. (1980). Attachment and loss Vol.3: Loss, sadness and depression. London: The Hogarth Press.

Bowlby, J. (1988). A secure base. New York: Basic Books.

Bretherton, I. (1985). Attachment theory: Retrospect and prospect. In I. Bretherton \& E. Waters (Eds.), Growing points of attachment theory and research. Monograph of the Society for Research in Child Development, 50 (1-2, serial No.209), 3-38.

Cassidy, J., \& Shaver, P.R. (Eds.). (1999). Handbook of attachment: Theory research and clinical implications. New York: Guilford Press. 
Colaizzi, P.F. (1978). Psychological research as the phenomenologist views it. In R. S. Valle \& M. King (Eds.), Existential-phenomenological alternatives for psychology (5th Ed.) (pp. 48-71). New York: Oxford University Press.

D'Cruz, H., Gillingham, P., \& Melendez, S. (2007). Reflexivity, its meanings and relevance for social work: A critical review of the literature. British Journal of Social Work, 37, 73-90.

Fahlberg, V. (1991). A child's journey through placement. London: British Agencies for Adoption and Fostering.

Foley, M.A. (2007). Bringing practice into theory: Social workers' experiences of bringing social work into attachment theory. Masters thesis, Massey University, Palmerston North, New Zealand.

Fonagy, P., Steele, M., \& Steele, H. (1991). Intergenerational patterns of attachment: Maternal representations during pregnancy and subsequent infant-mother attachments. Child Development, 62, 891-905.

Grigsby, R.K. (1994). Maintaining attachment relationships among foster care children. Families in Society: The Journal of Contemporary Human Services, May, 269-276.

Hendemark, C. (2004). Social workers' knowledge of attachment theory. Unpublished Masters Dissertation, California State University, Long Beach, California, U.S.A.

Hesse, E. (1996). Discourse, memory, and the adult attachment interview: A note with emphasis on the emerging cannot classify category. Infant Mental Health Journal, 17(1), 4-11.

Howe, D. (2005). Child abuse and neglect: Attachment, development and intervention. Basingstoke: Macmillan.

Howe, D., Brandon, M., Hinings, D., \& Schofield, G. (1999). Attachment theory, child maltreatment and family support. New Jersey: Lawrence Erlbaum Associates.

Longhofer, J. L., \& Floersch, J. (2004). The phenomenological practice gap: Practice guidelines, evaluation and clinical judgement. Qualitative Social Work, 3(4), 483-486.

Main, M. (1991). Metacognitive knowledge, metacognitive monitoring and singular (coherent) vs. multiple (coherent) model of attachment: Findings and directions for future research, in C.M. Parkes, J. Stevenson-Hinde, \& P. Marris (Eds.), Attachment across the life-cycle (pp. 127-159). London: Tavistock/ Routledge.

Meins, E., Fernyhough, C., Fradley, E., \& Turkey, M. (2001). Rethinking maternal sensitivity: Mothers' comments on infants' mental processes predict security of attachment at 12 months. Journal of Child Psychology and Psychiatry, 42, 637-48.

Mikulincer, M., Birnbaum, G., Woddies, D., \& Nachmias, O. (2000). Stress and accessibility of proximity-related thoughts: Exploring the normative and intra-individual components of attachment theory. Journal of Personality and Social Psychology, 78, 509-523.

Mikulincer, M., Gillath, O., \& Shaver, P. (2002). Activation of the attachment system in adulthood: Threat related primes increase the accessibility of mental representations of attachment figures. Journal of Personality and Social Psychology, 83, 881-895.

Mikulincer, M., \& Shaver, P. (2003). The attachment behavioural system in adulthood: Activation, psychodynamics and interpersonal processes. Advances in Experimental Psychology, 35, 53-152.

Nash, M., Munford, R., \& O’Donoghue, K. (Eds.). (2005). Social work theories in action. London: Jessica Kinglsey Publishers.

Redmond, B. (2004). Reflection in action: Developing reflective practice in health and social services. Aldershot, UK: Ashgate Publishing.

Ruch, G. (2005a). Reflective practice in contemporary child-care social work: The role of containment. British Journal of Social Work, 37, 659-680.

Ruch, G. (2005b). Relationship-based practice and reflective practice: Holistic approaches to contemporary child care and social work. Child and Family Social Work, 10, 111-123.

Ruch, G. (2007). Reflective practice in contemporary child-care social work: The role of containment. British Journal of Social Work, 37, 659-680.

Schofield, G., \& Beek, M. (2005). Providing a secure-base: arenting children in long term foster care. Attachment and Human Development, 7(1), 3-26.

Schofield, G., \& Beek, M. (2006). Attachment handbook for foster care and adoption. London: BAAF.

Sroufe, L.A., \& Waters, E. (1977). Attachment as an organisational construct. Child Development, 49, 1184-1199.

van Manen, M. (1990). Researching lived experience: Human science for an action sensitive pedagogy. New York: State University of New York Press.

Zeanah, C.H., Boris, N., Scott Heller, S., Hinshaw-Fuselier, S., Larrieu, J., Lewis, M., Palomino, R., Rovaris, M., \& Valliere, J. (1997). Relationship assessment in infant mental health. Infant Mental Health Journal, 18(2), 182-197. 